\section{Monitor ecosystem services from space}

We suggest that Earth observation should be used to monitor ecosystem services in the run-up to implementation of the United Nations Sustainable Development Goals (SDGs; see also A. K. Skidmore et al. Nature 523, 403-405; 2015).

A reliable Earth-observation framework would provide long-term spatial indicators of ecosystem services. It could capture changes in environmental and socio-economic features, for example by comparison with more than 40 years of Landsat satellite data and with information from new sensors such as the Sentinel fleet.

Earth observation could inform management decisions about how to resolve conflicting objectives that arise from the SDGs (see, for example, R. Bosch et al. Nature 523, 526-527; 2015). It would help in evaluating remote effects (teleconnections) for ecosystemservice provision and usage, such as whether biofuel production in one place creates biodiversity loss, pollution or deforestation elsewhere (see J. Liu et al. Science http://doi.org/627; 2015).

We need new forms of data integration and case-study synthesis. Earth-monitoring systems must be developed with input from environmental and social scientists to link up with existing knowledge, for example by relating ecosystem services to biodiversity.

Anna F. Cord, Ralf Seppelt Helmholtz Centre for Environmental Research (UFZ), Leipzig, Germany. Woody Turner NASA, Washington DC, USA. ralf.seppelt@ufz.de

\section{Biodiversity on canal route already at risk}

The Nicaraguan government is reviewing an environmental and social impact study for a proposed 300-kilometre canal to connect the Pacific and Atlantic oceans. As members of the specialist team who contributed to the 'baseline' biodiversity assessment for the study, we are in a position to respond to critics of the proposal (see, for example, A. Meyer and J. A. Huete-Pérez Nature 506, 287-289; 2014).

The internationally recognized environmental consulting firm ERM was commissioned to produce the study. Our impression is that ERM's dealings with its local counterparts, the Nicaraguan government and the company that owns the canal concession have been mutually transparent and professional.

Contrary to the depiction of the proposed canal route by Meyer and Huete-Pérez as a pristine wilderness, human impacts are strongly evident over its entire length, particularly from agriculture. This includes nationally and internationally protected areas and Lake Nicaragua, where several fish species are already in decline (T. B. Thorson Fisheries 7, 2-10; 1982; and M. T. McDavitt Shark News 14, 5; 2002).

We share many of the authors' concerns for environmental integrity and biodiversity along the proposed canal route. However, there were huge losses to these even before the canal project began, and this needs to be factored into the discussion. Jeffrey K. McCrary ${ }^{\star}$ Nicaraguan Foundation for Integral Community Development, Managua, Nicaragua. jmccrary2@yahoo.com

${ }^{\star}$ On behalf of 4 correspondents (see go.nature.com/nu2cjj for full list).

\section{Offsets: factor failure into protected areas}

Martine Maron and colleagues assume that a nation's commitment to establishing protected areas of biodiversity provides a suitable baseline for determining the "additionality" of any offset initiative based on habitat protection (Nature 523, 401-403; 2015). The evidence indicates otherwise.

A more realistic baseline would factor in the high probability that national biodiversity commitments will not be fulfilled (see M. Walpole et al. Science 325, 1503-1504; 2009). For example, national conservation commitments can be overridden by development commitments.

Documented trends and local conditions should be used to establish a baseline. Carbon offsets, for example, commonly derive baselines from historical average deforestation (see go. nature.com/rvdx $3 \mathrm{x}$ ). These baselines are typically revised every ten years.

We also disagree that developing countries should withdraw from the Convention on Biological Diversity (CBD) if they are unable to fund protected areas, because that would stop them engaging with other CBD targets. Moreover, honest accounting of offset benefits must occur at the local, regional and landscape levels where conservation is accomplished.

What is most needed in offset programmes is better enforcement, so that they do not become a 'licence to trash' (see A. Villaroya et al. PLoS ONE 9, e107144; 2014).

Joseph M. Kiesecker The Nature Conservancy, Fort Collins, Colorado, USA.

Bruce McKenney The Nature Conservancy, Charlottesville, Virginia, USA.

Peter Kareiva University of California, Los Angeles, USA. jkiesecker@tnc.org

\section{Galaxy $\gamma$-ray signal was not oversold}

We argue that Jan Conrad's depiction of our preprint (http:// arxiv.org/abs/1503.02320;2015) as a case study in 'crying wolf' lacks accuracy and credibility (Nature 523, 27-28; 2015).

Based on public data from NASA’s Fermi Large Area
Telescope (LAT), we reported a $\gamma$-ray signal from the dwarf galaxy Reticulum II. Conrad characterizes our work as "the latest dark-matter discovery claim" and criticizes the "misuse" of public data at a time when an update from the Fermi collaboration "was imminent".

Nowhere do we claim to have discovered dark matter. Rather, our paper is devoted to quantifying the probability that the observed signal is due to random fluctuation. Our closing paragraph says "it would be premature to conclude [the signal] has a dark matter origin", then identifies future work necessary to establish such a discovery.

Our use of public data is concordant with the principles of 'reproducibility' Conrad invokes. Nevertheless, he compares our work unfavourably to a paper by the Fermi-LAT and Dark Energy Survey (DES) collaborations, who calculate a larger probability of background fluctuation (see preprint at http://arxiv.org/abs/1503.02632; 2015 and A. Drlica-Wagner et al. Astrophys. J. 809, L4; 2015). Conrad did not disclose that he was initially an author on their submitted paper. He states that the Fermi-LAT/DES result is based on "more comprehensive re-analysis of the same data"; however, theirs is a separate analysis of different data that were released 15 weeks after both papers appeared, preventing confirmation of their results in the interim. Meanwhile, only our result was reproducible (see, for example, D. Hooper and T. Linden, preprint at http://arxiv.org/ abs/1503.06209; 2015).

Moreover, our findings are now published in the peer-reviewed literature (Phys. Rev. Lett. 115, 081101; 2015).

Alex Geringer-Sameth ${ }^{*}$ Carnegie Mellon University, Pittsburgh, Pennsylvania, USA. alexgs@cmu.edu ${ }^{*}$ On behalf of 7 correspondents (see go.nature.com/n6gont for full list). 